\title{
MODELLING THE CYCLIC RESPONSE OF RC BEAM-COLUMN MEMBERS
}

\author{
Diego Miramontes De León ${ }^{(1)}$, \\ Omar Merabet and Jean Marie Reynouard ${ }^{(2)}$
}

\begin{abstract}
RESUMEN
La mayoría de los modelos cíclicos uniaxiales formulados en variables globales $(M, \phi)$ toman en cuenta varios fenómenos esenciales de las secciones de Concreto Reforzado. Sin embargo, a menudo se asumen descargas elásticas lineales. Esta suposición involucra una disipación nula de energía para cargas cíclicas no alternantes, mientras que los resultados observados muestran degradación de resistencia y disipación de energía. Más aun, para cargas cíclicas alternantes como las sísmicas, la disipación de energía observada está relacionada con el comportamiento no lineal tanto en carga como en descarga. La falta de atención a este comportamiento produce deformaciones residuales más pequeñas $\mathrm{y}$, en consecuencia, un comportamiento histerético diferente. Con el propósito de lograr una predicción más realista, se incluye un comportamiento de descarga bilineal a una ley cíclica. El trabajo está basado en un modelo previamente implementado en el programa de uso general CASTEM2000 del Comisariado Francés para la Energía Atómica (CEA). El modelo se caracteriza por una curva envolvente trilineal y un conjunto de reglas cíclicas. La pérdida de rigidez y la degradación de resistencia tanto en la rama ascendente como en la descendete y el amortiguamiento histerético dependen directamente del nivel e historia de carga aplicada. Las ecuaciones de movimiento se resuelven por el método de Newmark centrado y las condiciones de borde se imponen por medio de los multiplicadores de Lagrange. En este trabajo se describe la estrategia de análisis no lineal usando los multiplicadores de Langrange y el modelo cíclico propuesto. Los resultados numéricos se han comparado en experimentos con varios miembros estructurales y sub-ensambles sujetos a diferentes condiciones de carga. La comparación muestra el interés del modelo modificado propuesto.
\end{abstract}

\begin{abstract}
Most of the uniaxial cyclic models formulated in generalized variables $(M, \quad)$ take into account several essential phenomena of RC sections. Nevertheless, linear elastic unloading is often assumed. This assumption disregards energy dissipation for non alternating cyclic loading, while
\end{abstract}

Artículo recibido el 26 de septiembre de 2000 y aprobado para su publicación el 11 de mayo de 2001. Se aceptarán comentarios y/o discusiones al artículo hasta cinco meses después de su publicación.

(1) Fac. Ingeniería, Universidad Autónoma de Zacatecas, México

(2) URGC-Structures, Institut National des Sciences Appliquées de Lyon, France 
observed results show strength degradation and energy dissipation. Furthermore, for alternating cyclic loading as earthquakes, the observed energy dissipation is related to a non-linear behaviour at loading and unloading. The consequence of this behaviour produces smaller theoretical residual strains and, consequently, a different hysteretic behaviour. In order to account for a more realistic prediction, a bilinear branch at unloading is included in a cyclic law. The work is based on a previous model implemented into the general purpose program CASTEM2000 of the French Commission of Atomic Energy (CEA). The model is characterized by a trilinear envelope curve and a set of cyclic rules. The strength and stiffness degradation in the hardening and the softening branches as well as the hysteretic damping are directly dependent on the level and history of loading. The solution of the dynamic equations is based on the implicit Newmark's method and the limit conditions are imposed by the Lagrange multipliers. In this paper, the non-linear strategies applying the Lagrange multipliers and the proposed cyclic model are presented. The numerical results have been compared with several structural members and subassemblies subjected to different loading conditions. This comparison confirms the importance of the proposed modified model.

Keywords : seismic loading, energy dissipation, degradation process.

\section{INTRODUCTION}

Reinforced concrete frames are widely used for buildings in high seismic zones. The inelastic demands due to the dynamic loading require efficient numerical methods to carry out a non-linear analysis of the whole structure. This analysis is needed to identify correctly the cyclic degradation process and/or the imminent failure of the structural system. Local or semi-local methods have been successfully applied to describe the non-linear behavior of RC structures (Wolf \& Song, 1996; Koh et al. 1997; Spacone et al. 1996a,b; Taucer et al. 1996; Cheok et al. 1998). Nevertheless, the non-linear analysis of whole structures subjected to dynamic loads, represents a high constraint due to the volume of non-linear calculations needed to integrate the equilibrium equations for each time step.

In contrast, global models are formulated in generalized variables (Miramontes et al. 1996). These models take into account the integrated concrete and steel properties. As a result, the integration of stresses at cross section level is eliminated and the number of points defining the behaviour law is reduced. The global models are formulated considering simplified kinematic hypothesis (Navier-Bernoulli or Timoshenko for beams, Kirchhoff-Love or Reissner-Mindlin for shells). The reinforced concrete behaviour is described in generalized variables as uniaxial behaviour laws based on experimental observations $(N, \quad),(V, \quad),(M$,$) . The reduced CPU time$ required and the adequate simulation of global hysteretic behaviour make these models an attractive tool-kit for sequentially non-linear dynamic analysis of complete structures. 
Most of the previous global models (Takeda et al. 1970; Mork, 1994) neglect the presence of residual strains before yielding. Hence, the stiffness degradation and energy dissipation processes begin after the yield condition. The strength reduction is modelled by constant parameters or constant reloading points independent of the cyclic loading history. A better description is based on the accumulated hysteretic energy. However, the effect of this quantity for subsequent cyclic loading for a fixed strain level should vanish in order to describe the cyclic stabilisation phenomenon.

A previous proposed model (Miramontes et al., 1996) based on the generalized variables M- $\phi$. where generalized strain means curvature, extends the degradation rule for the unloading stiffness before yielding. Therefore, residual strains reflect a more realistic behaviour of RC cracked members and at the same time, a uniform evolution of stiffness up to failure is assured. The pinched shape associated with diagonal shear cracks is modelled by means of the previous parameter $\alpha_{\mathrm{p}}$ proposed by Roufaiel and Meyer (1987) based on the strong correlation found between the degree of pinching and the relative magnitude of shear at the section. Additionally, the strength reduction, stiffness degradation and energy dissipation are directly dependent on the load level and on the cyclic loading (Miramontes et al., 1996), which are described by a cyclic parameter $\beta$.

\section{NON-LINEAR RESOLUTION STRATEGIES}

In CASTEM2000 code (CEA, 1990), different data structures are used to represent the objects needed in the finite element analysis : nodes, meshes, element fields (defined in the points of integration laws), point fields, stiffness and mass matrix, etc. The main numerical procedures can be summarized in :

- Treatment of limit conditions

- Algorithm for external equilibrium forces

- Step by step time integration process

\section{Treatment of limit conditions}

The limit conditions are treated in CASTEM2000 by the Lagrange multipliers in order to obtain a symmetric and well posed system of equations, which means no null terms in the diagonal. In the usual procedure, the minimization of the function defined by the potential energy is modified in order to satisfy not only the static limit conditions and the differential equilibrium equations but also the mathematical restrictions that arise by these constraints. 
The potential energy function $\Pi^{\prime}$ to be minimized is :

$\Pi^{\prime}=\Pi_{\text {initial }}+\int_{S_{u}} \operatorname{L} \cdot g(\vec{q}) \cdot d s$

with $\quad \mathrm{L}:$ the function for the Lagrange multipliers

$\mathrm{g}$ : the function for $\vec{q}$ which includes the mathematical restrictions

The imposed limit conditions can be seen as a null linear combination of displacements :

$[A] \cdot\left\{q_{i}\right\}-\{b\}=0$

where $[A]$ is a $\mathrm{m} \times \mathrm{n}$ matrix, $\left\{q_{i}\right\}$ the $n$ degrees of freedom subjected to the imposed conditions and $\{b\}$ the remainder degrees of freedom. The augmented function is :

$\Pi^{\prime}=\frac{1}{2}\{q\}^{T} \cdot[K] \cdot\{q\}-\{q\}^{T} \cdot\left\{f_{e}\right\}+\{L\}^{T}\left([A] \cdot\left\{q_{i}\right\}-\{b\}\right)$

where $[\mathrm{K}]$ is the stiffness matrix and $\left\{f_{e}\right\}$ is the external force vector. However, minimizing $\Pi$ ' leads to a not well posed equation system, with at least, one null value on the diagonal. In order to avoid this problem, a new artificial condition is included in the variables where the multipliers are expressed as a linear combination. This condition is given by $\lambda_{1}=\lambda_{2}$. Then, the new augmented function is :

$\Pi^{\prime}=\frac{1}{2}\{q\}^{T} \cdot[K] \cdot\{q\}-\{q\}^{T} \cdot\left\{f_{e}\right\}+\left\{L_{1}\right\}^{T}\left([A] \cdot\left\{q_{i}\right\}-\{b\}\right)+\left\{L_{2}\right\}^{T}\left(\lambda_{1}-\lambda_{2}\right)$

If the linear combination of $\lambda$ are chosen as :

$\mathrm{L}_{1}=\lambda_{1}+\lambda_{2}$

$\mathrm{L}_{2}=\lambda_{1}-\lambda_{2}$.

The minimization of $\Pi$ ' yields a well posed system equation :

$$
\left\{\begin{array}{l}
{[K] \cdot\{q\}=\left\{f_{e}\right\}-[A]^{T} \cdot\left[\lambda_{1}+\lambda_{2}\right]} \\
{[A] \cdot\{q\}-\{b\}=0} \\
\lambda_{1}=\lambda_{2}
\end{array} \Leftrightarrow\left[\begin{array}{ccc}
K & A^{T} & A^{T} \\
A & I & -I \\
A & -I & I
\end{array}\right] \cdot\left[\begin{array}{c}
q \\
\lambda_{1} \\
\lambda_{2}
\end{array}\right]=\left[\begin{array}{c}
f_{e} \\
b \\
b
\end{array}\right]\right.
$$


where $[A]$ is completed by $\mathrm{n}-\mathrm{m}$ zero columns and the forces are associated to the kinematic imposed conditions by : $-A^{T} \cdot\left[\lambda_{1}+\lambda_{2}\right]$.

\section{Equilibrium iterative procedure}

This procedure search for the displacement increment (including the $\lambda$ multipliers) which gives an equilibrium condition between the internal and the external applied forces (with the reaction forces associated to $\lambda$ values). At the same time, the degrees of freedom for the kinematic conditions should be verified. During a non-linear analysis, the tangent relationship between forces and displacements depends on the degradation of the stiffness throughout the structure. This tangent operator is not always easy to evaluate according to the formulated behavioural laws. In Castem2000, the displacement vector is corrected solving the next equation system :

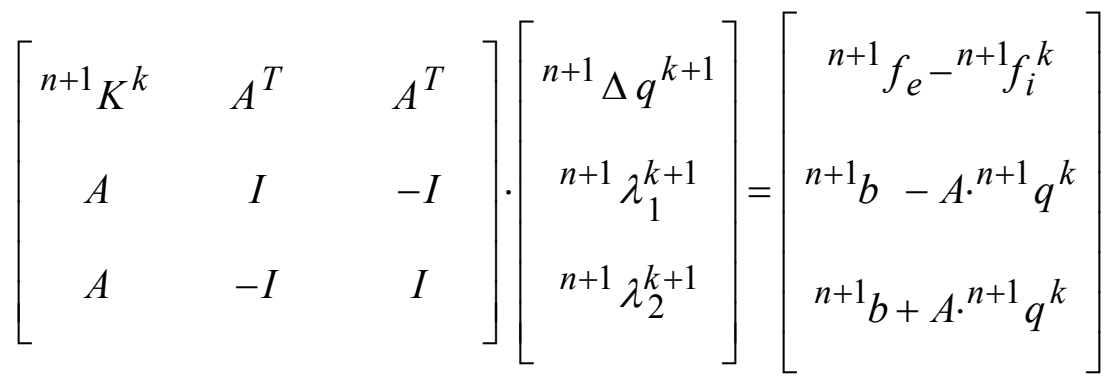

where ${ }^{n+1} q^{k}$ is the total displacement at the iteration $k\left({ }^{n+1} q^{k}={ }^{n} q+\sum_{j=1}^{k} \Delta q^{j}\right)$

- ${ }^{n+1} f_{i}^{k}$ is the internal force at the iteration $k$.

- ${ }^{n+1} K^{k}$ is the stiffness matrix at the iteration $k$. 
the left upper index $n+1$ means the increment step and the right upper index $k$ means the iteration at the increment step.

If a continuos behavioural laws were used, and the tangent stiffness matrix $K^{k}$ is evaluated, the equation 6) would becomes the Newton-Raphson method, with a quadratic convergence. Nevertheless, the behavioural laws for concrete need special attention due to the strong variations of the stiffness (§3). Hence the initial tangent stiffness ${ }^{0} K$ can be used as the iterative operator $K^{k}$. The convergence of this process is not efficient. Two new algorithms can be used to improve the performance of this strategy : the previous displacement increment and the convergence acceleration. Due to its more general applicability, only the first procedure will be discussed in this paper.

\section{Previous displacement increment}

At the first iteration, the system 6) close to convergence at the increment $n+1$ becomes :

$$
\left[\begin{array}{ccc}
{ }^{0} K & A^{T} & A^{T} \\
A & I & -I \\
A & -I & I
\end{array}\right] \cdot\left[\begin{array}{c}
\Delta q^{1} \\
\Delta \lambda_{1}^{1} \\
\Delta \lambda_{2}^{1}
\end{array}\right]=\left[\begin{array}{c}
{ }^{n+1} f_{e}-{ }^{n} f_{e} \\
n+1 \\
{ }^{n+1} b+{ }^{n} b
\end{array}\right]={ }^{n+1} \Delta f
$$

If ${ }^{0} K$ is not close to the real stiffness at the beginning of the increment $n+1$, then the vector $\left[\Delta q^{1}, \Delta \lambda_{1}^{1}, \Delta \lambda_{2}^{1}\right]$ will not be close to the final solution either. It is always possible to get a better first estimation using the tangent stiffness found in the previous increment ${ }^{\mathrm{n}}[K]$. However, knowing the previous force and displacement increments is not needed to calculate the tangent stiffness ${ }^{\mathrm{n}}[K]$, it is only necessary to take a fraction of the precedent increment as :

$$
\left\{\begin{array}{l}
{ }^{n}[K] \cdot\left[{ }^{n+1} \Delta q^{1}\right]=\left[{ }^{n+1} \Delta f\right] \\
{ }^{n}[K] \cdot\left[{ }^{n} \Delta q\right]=\left[{ }^{n} \Delta f\right]
\end{array} \Rightarrow\left[{ }^{n} \Delta q\right]^{-1} \cdot\left[{ }^{n+1} \Delta q^{1}\right]=\left[{ }^{n} \Delta f\right]^{-1} \cdot\left[{ }^{n+1} \Delta f\right]\right.
$$

Hence, if $\left[{ }^{\mathrm{i}} \Delta f\right]={ }^{\mathrm{i}} \Delta \mathrm{t} .\left[f_{0}\right] \forall \mathrm{i}$, then $\left[{ }^{n+1} \Delta q^{1}\right]=\frac{{ }^{n+1} \Delta f}{{ }^{n} \Delta f} \cdot\left[{ }^{n} \Delta q\right]$

It can be seen that $\left[{ }^{\mathrm{n}} \Delta q /{ }^{\mathrm{n}} \Delta f\right]$ is ${ }^{\mathrm{n}}[K]^{-1}$ which gives a better first estimation of the displacement vector $q$. This procedure is called in Castem 2000 initiation by the precedent solution. 


\section{Step by step time integration procedure}

The solution of the dynamic equations is based on the implicit Newmark's average acceleration method with $\alpha_{\text {Newmark }}=0.5$ and $\beta_{\text {Newmark }}=0.25$. The solution of the dynamic equilibrium equation is generally carried out separating the time of spatial coordinates. The spatial coordinates are discretized by finite elements, while the time coordinates are integrated by a finite difference method. The system equation to be solved at each time step is :

$[M] \cdot\{\ddot{q}\}+[C] \cdot\{\dot{q}\}+\left\{F_{\text {int }}\right\}=\{P(t)\}$

where $M$ and $C$ are the mass and damping matrix respectively. The non-linearity phenomena can be included by the finite differences method of the static equilibrium condition (eq. 6) as follows:

The convergence acceleration leads to

$$
\begin{cases}{ }^{n+1} \dot{q}= & { }^{n} \dot{q}+\frac{\Delta t}{2}\left({ }^{n} \ddot{q}+{ }^{n+1} \ddot{q}\right) \\ { }^{n+1} q= & { }^{n} q+\Delta t^{n} \dot{q}+\frac{\Delta t^{2}}{4}\left({ }^{n} \ddot{q}+{ }^{n+1} \ddot{q}\right)\end{cases}
$$

These equations can be evaluated at the instant $n+1$ as a function of the values at step $n$, where the displacement at the increment $n+1$ is the only unknown :

$$
\left\{\begin{array}{l}
{ }^{n+1} q={ }^{n+1} q \\
{ }^{n+1} \dot{q}=\frac{2}{\Delta t}\left({ }^{n+1} q-{ }^{n} q\right)-{ }^{n} \dot{q} \\
n+1 \ddot{q}=\frac{4}{\Delta t^{2}}\left({ }^{n+1} q-{ }^{n} q\right)-\frac{4}{\Delta t} \cdot{ }^{n} \dot{q}-{ }^{n} \ddot{q}
\end{array}\right.
$$

With these expressions and equation 9) the dynamic equilibrium system at the increment $n+1$ is :

$$
\left(\frac{4 M}{\Delta t^{2}}+\frac{2 C}{\Delta t}\right) \cdot{ }^{n+1} \Delta q+{ }^{n+1} \Delta f_{i}={ }^{n+1} f_{e}+\underline{M^{n} \ddot{q}+C^{n} \dot{q}}-{ }^{n} f_{i}+\frac{4 M}{\Delta t} \dot{q}
$$

where ${ }^{n+1} \Delta q$ displacement increment : ${ }^{n+1} q-{ }^{n} q$

and $\quad{ }^{n+1} \Delta f_{i}$ internal force increment : ${ }^{n+1} f_{i}-{ }^{n} f_{i}$

In order to minimize the time consuming and the space computation requirements, the vector acceleration can be eliminated using the equilibrium solution of precedent step. The second and third terms of the right hand expression in 12) are modified as : 


$$
\begin{aligned}
& M^{n} \ddot{q}+C^{n} \dot{q}+{ }^{n} f_{i}={ }^{n} f_{e} \\
& M^{n} \ddot{q}+C^{n} \dot{q}={ }^{n} f_{e}-{ }^{n} f_{i}
\end{aligned}
$$

Then, the equation 12) becomes :

$\left(\frac{4 M}{\Delta t}{ }^{2}+\frac{2 C}{\Delta t}\right) \cdot n+1_{\Delta q+}{ }^{n+1} \Delta f_{i}=F_{c}-n_{f_{i}}$ where $: F_{c}={ }^{n+1} f_{e}{ }^{+{ }^{n} f_{f}}{ }^{-n_{f_{i}}}+\frac{4 M}{\Delta t} n_{q}$

At the first iteration of displacement increment, the stiffness ${ }^{0} K$ can be used, where ${ }^{{ }^{n+1}} \Delta f_{\mathrm{i}}$ is replaced by ${ }^{0} K^{\mathrm{n}+1} q^{1}$ transforming the equation 14$)$ as :

$\hat{K}^{n+1} \Delta q^{1}=F_{c}{ }^{n}{ }^{n} f_{i}$

with $\hat{K}=\frac{4 M}{\Delta t^{2}}+\frac{2 C}{\Delta t}+{ }^{0} K$

Due to non-linearity, the internal forces ${ }^{n+1} f_{i}^{1}$ can not verify the equilibrium condition. Then the corrective solution of ${ }^{\mathrm{n}+1} \Delta q^{2}$ which satisfies eq. 14) is :

$\left(\frac{4 M}{\Delta t^{2}}+\frac{2 C}{\Delta t}\right) \cdot\left({ }^{n+1} \Delta q^{1}+{ }^{n+1} \Delta q^{2}\right)+{ }^{n+1} \Delta f_{i}^{2}=F_{c}-{ }^{n} f_{i}$

Using always ${ }^{0} K,{ }^{n+1} \Delta f_{i}^{2}$ is replaced by ${ }^{n+1} \Delta f_{i}{ }^{1}+{ }^{0} K^{n+1} \Delta q^{2}$ giving :

$$
\begin{gathered}
\left(\frac{4 M}{\Delta t^{2}}+\frac{2 C}{\Delta t}+{ }^{0} K\right) \cdot{ }^{n+1} \Delta q^{2}=F_{c}-{ }^{n} f_{i}-\left({ }^{n+1} f_{i}^{1}-{ }^{n} f_{i}\right)-\left(\frac{4 M}{\Delta t^{2}}+\frac{2 C}{\Delta t}\right){ }^{n+1} \Delta q^{1} \\
\Leftrightarrow \hat{K}^{n+1} \Delta q^{2}=F_{c}-{ }^{n+1} f_{i}{ }^{1}-\left(\frac{4 M}{\Delta t^{2}}+\frac{2 C}{\Delta t}\right)^{n+1} \Delta q^{1}
\end{gathered}
$$

At any iteration $k$, it is found :

$$
\hat{K}^{n+1} \Delta q^{k+1}=F_{c}{ }^{n+1} f_{i}^{k}-\left(\frac{4 M}{\Delta t^{2}}+\frac{2 C}{\Delta t}\right)^{n+1} \Delta q^{k}
$$

and at the equilibrium :

$$
\hat{K}^{n+1} \Delta q^{k+1}+{ }^{n+1} \Delta f_{i}^{k}=F_{c}-{ }^{n} f_{i}
$$

In practice, the iteration process stops when the normalized residue (the right hand member of equation 19) is sufficiently negligible according to a specified precision.

In order to have a full accordance to expression 6) the vector ${ }^{n+1} f_{e}$ should be completed by the terms ${ }^{n+1} b$ (the remainder displacements), the internal force ${ }^{n+1} f_{i}^{k}$ by ${ }^{n+1} q^{k}$ and this last by ${ }^{n+1} \lambda_{\cdot} \cdot{ }_{1 \text { and } 2}$ (the Lagrange multipliers). 


\section{BASIC HYSTERETIC MODEL}

The non-linear analysis depicted in $\S 2$ requires the definition of behavioural laws to be included into the step by step integration process. According to the necessity of a global analysis (§1), a beam finite element and a global cyclic model are adopted. The beam element is formulated by a classical finite element approach defined by six degrees of freedom at each node. For the forces associated at each degrees of freedom, only the moment-curvature relationships are considered as non-linear. The principal features of this non-linear relationship are described in this section.

The model is characterized by a trilinear envelope curve and a set of cyclic rules (Figure 1). The characteristic points of the envelope curve, which should be evaluated by a non-linear limit analysis, are defined by three critical strain conditions at cross section level; i.e. cracking of concrete $\left(M_{\mathrm{cr}}, \phi_{\mathrm{cr}}\right)$, yielding of tensile steel $\left(M_{\mathrm{y}}, \phi_{\mathrm{y}}\right)$ and the ultimate strain of compressed concrete $\left(M_{\mathrm{u}}, \phi_{\mathrm{u}}\right)$. These points are calculated on the assumption that plane sections remain plane even up to incipient failure and assuming that strain-stress relationships for concrete and steel are known. In addition to the assumption of plane sections, a perfect bond between concrete and steel is assumed. A non-linear analysis of the reinforced concrete section (Miramontes,1996), leads to the ultimate compressive strain of concrete which define the point where the softening behaviour of the envelope curve starts. The effect of a constant axial force due to gravity loads is taken into account during the envelope curve definition. This assumption limits the applicability of the model to the structures with negligible variation of axial forces.

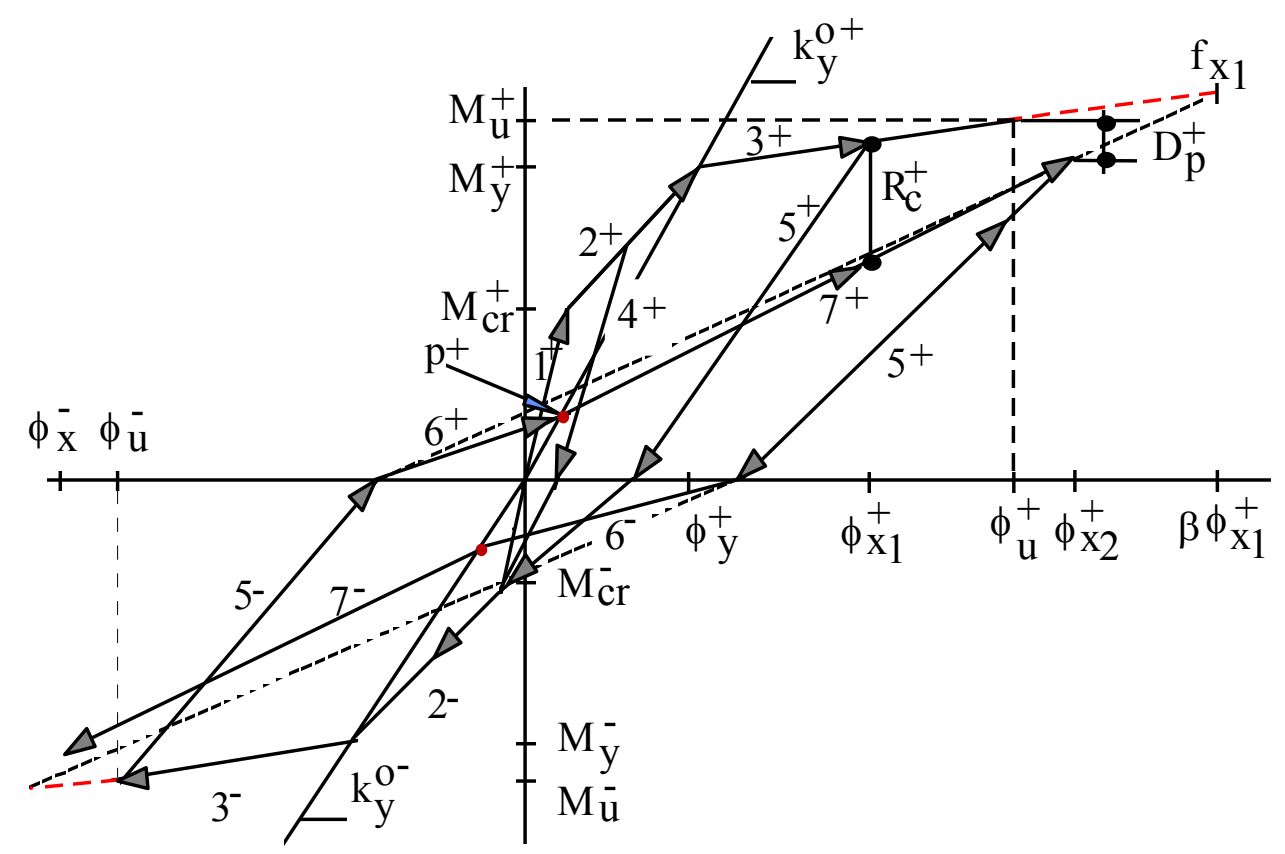

Figure 1. Basic hysteretic model 
The model is completed by a set of cyclic rules (Figure 1). The stage behaviour at level section related with each branch are : 1- elastic behaviour before cracking; 2- cracked concrete before yielding of steel; 3- post-steel yielding; 4- unloading before yielding; 5- linear damaged unloading; 6- reverse loading before pinching; 7- reverse loading after pinching. The evolution of cyclic behaviour is controlled by a cyclic parameter $\beta$ defined in terms of a damage index, an accommodation factor and the number of cycles with amplitude inferior to the maximum strain (curvature) ever experienced. This parameter allows the description of monotonic and cyclic response for both small and large deformations $\left(M_{y} \leq M_{x} \leq M_{u}\right)$, including the post-peak regimen $\left(M_{x}>M_{u}\right)$.

The parameter $\beta$ is used to define a focal point $\phi^{i}$ associated with a strain level $\beta \phi_{\max }$ and depends on a damage index $D_{\max }$, on an accommodating factor $A_{\max }$ and on the number of cycles $(i \ldots n)$, experienced up to the maximum strain level (Figure 2.a):

$\beta=1+\sum_{i}^{n}\left[D_{\max } A_{\max }\right]^{i}$

then

$\beta=1+\sum_{i}^{n}\left[\frac{E_{\max }}{E_{u}} \frac{M_{\max } \phi_{\max }}{M_{u} \phi_{u}}\right]^{i}$

where $E_{\max }$ and $E_{u}$ are the total absorbed energy at the $\phi_{\max }$ and $\phi_{u}$ strains respectively. Every time the maximum strain $\phi_{\max }$ ever experienced is updated, $i$ and $\beta$ are initialized to zero and one respectively, while $D_{\max }$ and $A_{\max }$ remain constant throughout the cyclic loading. The value of $\beta$ becomes stable after 4 or 5 cycles at $\phi_{y} \leq \phi_{\max } \leq 0.5 \phi_{u}$ with a reduction strength of about

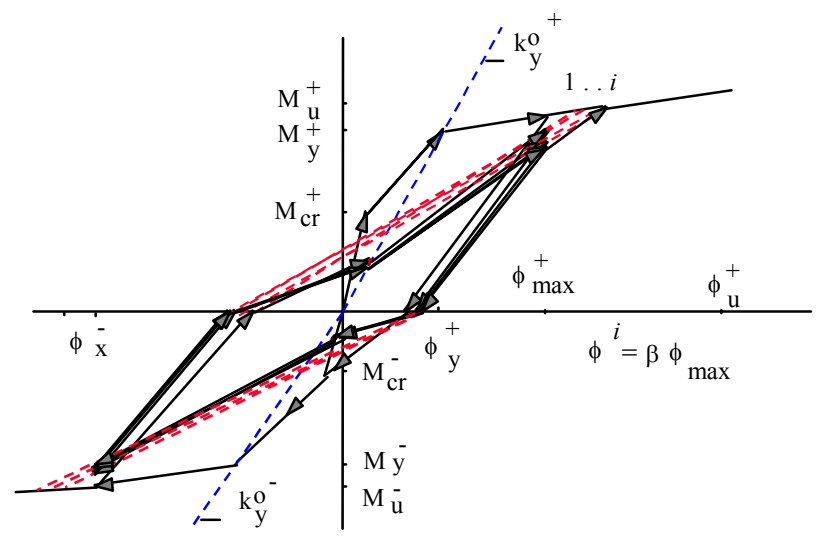

Figure 2a. Focal point evolution $\phi^{\mathrm{i}}$ before the critical strain $\phi_{\mathrm{u}}$

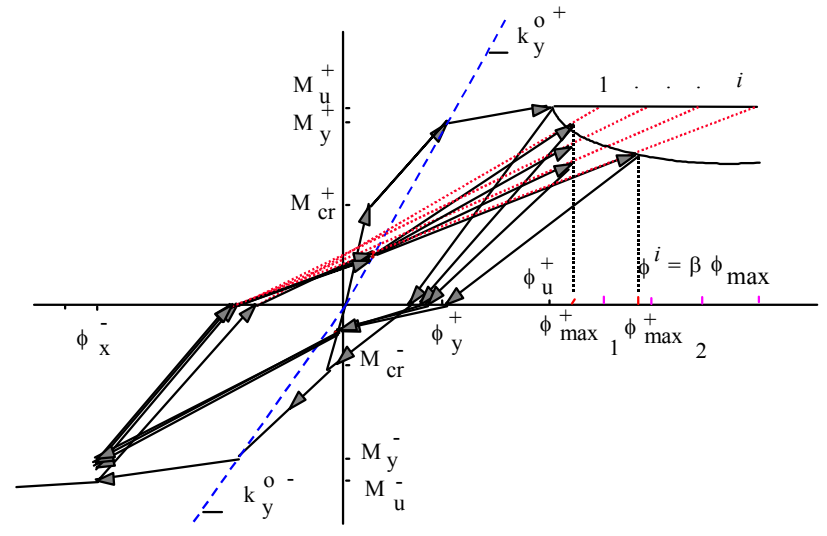

Figure 2b. Focal point evolution $\phi^{\mathrm{i}}$ after the critical strain $\phi_{\mathrm{u}}$ 
$5 \%$, whereas in the case of strain levels close to failure $\left(0.9 \phi_{u} \leq \phi_{\max } \leq \phi_{u}\right)$, the accommodation appears only after about twenty cycles with a strength reduction close to $40 \%$.

The parameter $\beta$ previously defined allows to manage in the post-peak regime the envelope curve and the reduced strength $M_{u}^{\prime}$ of the cross section at the same time (Figure 2.b). In this case, $\beta$ is calculated letting $E_{\max }=E_{u}, M_{\max }=M_{u}^{\prime}$ and $\phi_{\max }=\phi_{u}^{\prime}$. Accordingly, $\beta=1+n$ (with $n \geq 1$ ) leads generally to a quick strength reduction of $M_{u}^{\prime}$ throughout the cyclic load, accentuated by the importance of the strains $\left(\phi>>\phi_{u}\right)$. In this way, the effect of $\beta$ is defined by the envelope curve (cross section characteristics), the maximum strain ever experienced and the number of cycles applied (amount of absorbed energy).

\section{MODIFIED UNLOADING BRANCHES}

Experimental results observed on structural members such beams, columns and subassemblies have shown that the energy dissipation depends strongly on the non-linear behaviour at loadingunloading (Figure 3). This phenomenon is present in several load conditions and different relationships (load-displacement, moment-curvature, shear force-diagonal strain, etc.) (Chronopoulos \& Vintzileou, 1995; Bozinovski, 1995; Park et al. 1982). Nevertheless, this effect tends to disappear when softening behaviour is reached (Figure 4).

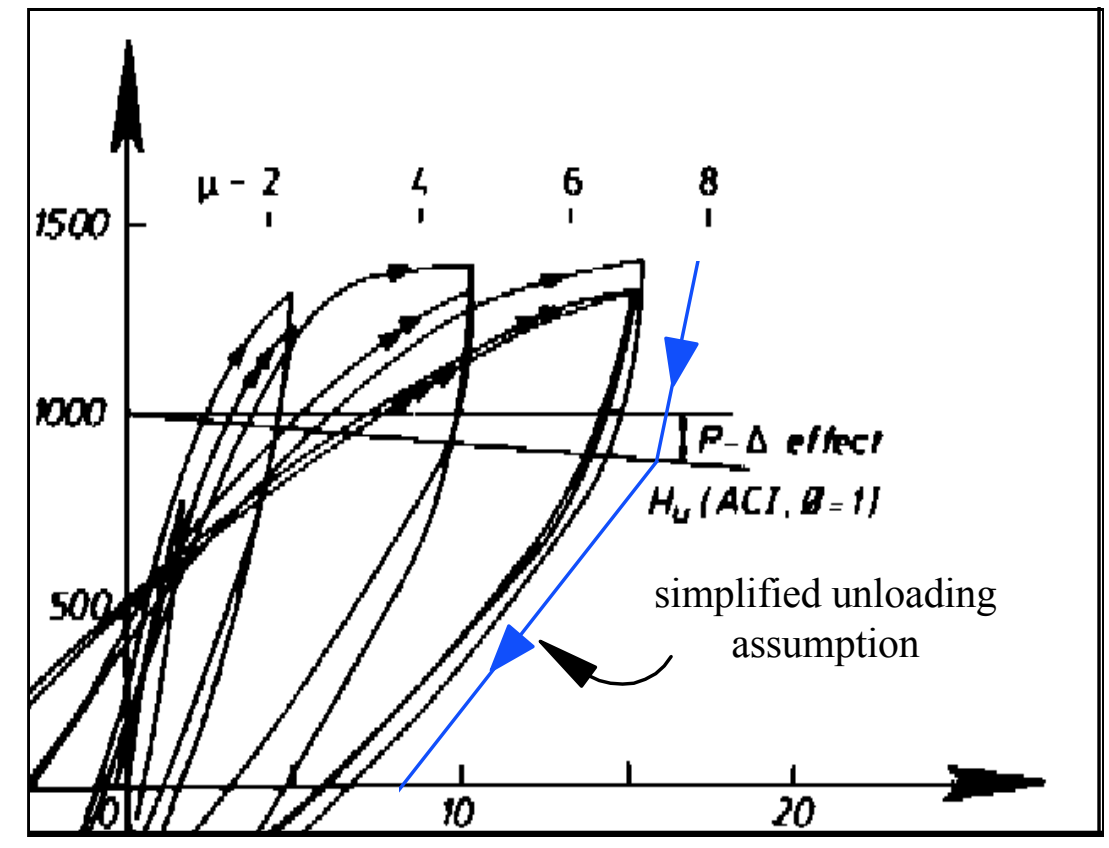

Figure 3. Experimental evidence of non-linear unloadings (Park et al. 1982) 


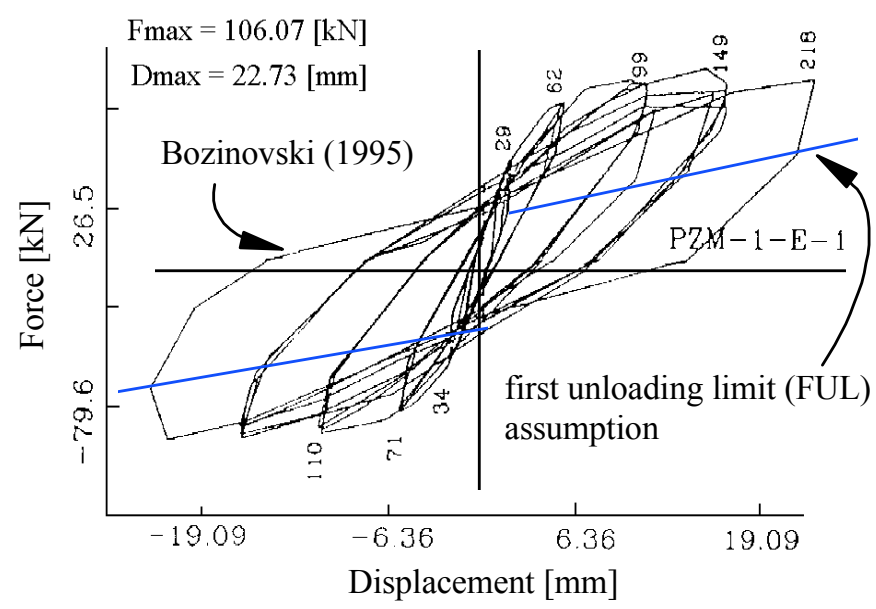

Figure 4. Statement of FUL based on experimental observations

Elastic linear unloading involves null energy dissipation for non alternating cyclic loading-reloading (branch 7 in Figure 1), while observed results show strength degradation and energy dissipation (Sinha et al., 1964). Furthermore, for alternating cyclic loading as earthquakes, the observed energy dissipation is related to a non-linear behaviour at loading and unloading (Park et al., 1972). This behaviour increases the energy dissipation with higher residual strains by cycle. The misleading of this behaviour produces smaller theoretical residual strains and, consequently, a different hysteretic behaviour. Therefore, it is necessary to include this nonlinear behaviour in order to improve the cyclic response of uniaxial models for alternating and non alternating cyclic loading.

Kinematic hardening plasticity-based models (Miramontes et al., 1997) consider this nonlinear unloading by at least two branches : a non damaged elastic one (unloading inside the yield surface) and a second damaged elastic branch (plasticity). However, it has been seen that even elastic unloading should take into account all previous inelastic incursions. In order to account for more realistic behaviour in uniaxial models, branch 7 (Figure 1) is transformed in a bilinear curve at unloading which is proposed in addition to previous cyclic laws (Figure 5). For the first branch a damaged initial stiffness is used $\alpha \mathrm{k}_{0}$, whereas in the second one, the damage parameter aproposed in earlier models (Taketa et al., 1970; Roufaiel \& Meyer, 1987) is applied to a previously degraded unloading stiffness $\mathrm{k}$. In this way, all unloading branches account for stiffness degradation accordingly to the level of inelastic incursions.

It has been also observed that the first damaged branch (Figure 4) is present above a limit value. This limit can be considered as the difference between the maximum moment capacity and the cracking moment. Consequently, for incursions into the softening branch the non-linear unloading tends to disappear. As a result, linear unloading is found when the maximum strength stands below this limit (FUL-first unloading limit). The new unloading stiffnesses are (in absolute value): 


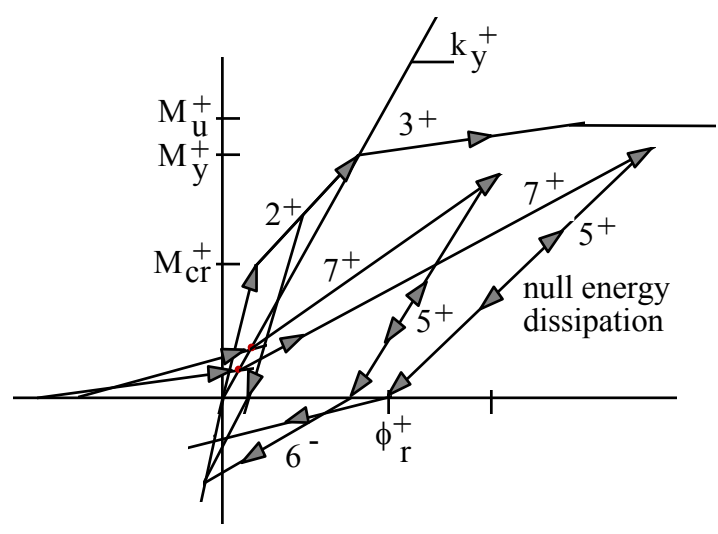

a) Damaged linear unloading

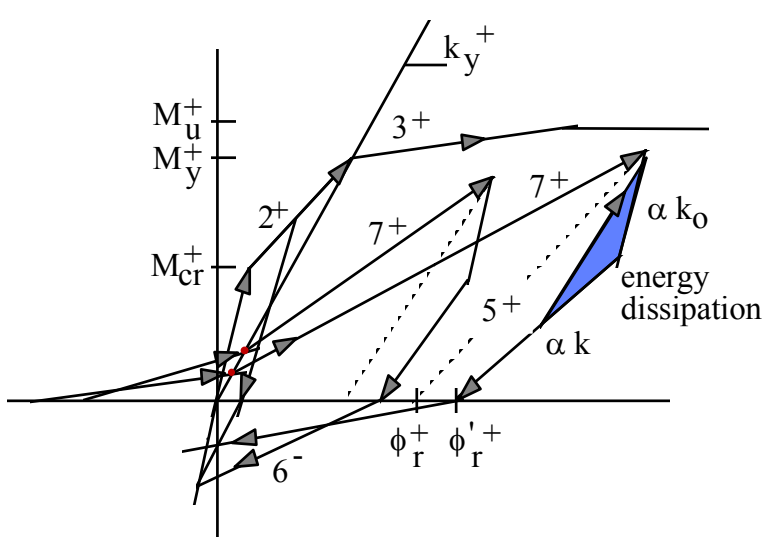

b) Damaged bilinear unloading

Figure 5. Modified unloading of a uniaxial cyclic model

First unloading branch $\left(M_{\mathrm{cr}} \leq \mathrm{M}_{\mathrm{x}} \leq \mathrm{M}_{\mathrm{u}}\right)=\alpha \mathrm{k}_{\mathrm{o}}$

Second unloading branch $\left(\mathrm{M}_{\mathrm{x}}<\mathrm{M}_{\mathrm{cr}}\right)=\alpha \mathrm{k}$

The first unloading limit tends to describe the continuous deterioration of the material when severe inelastic incursions occur. This loading produces a complete degradation of unloading stiffness due to propagation of the plastic zone. All the other cyclic rules remain unchanged. Taking into account these observations, the proposed uniaxial cyclic law is given in Figure 6.

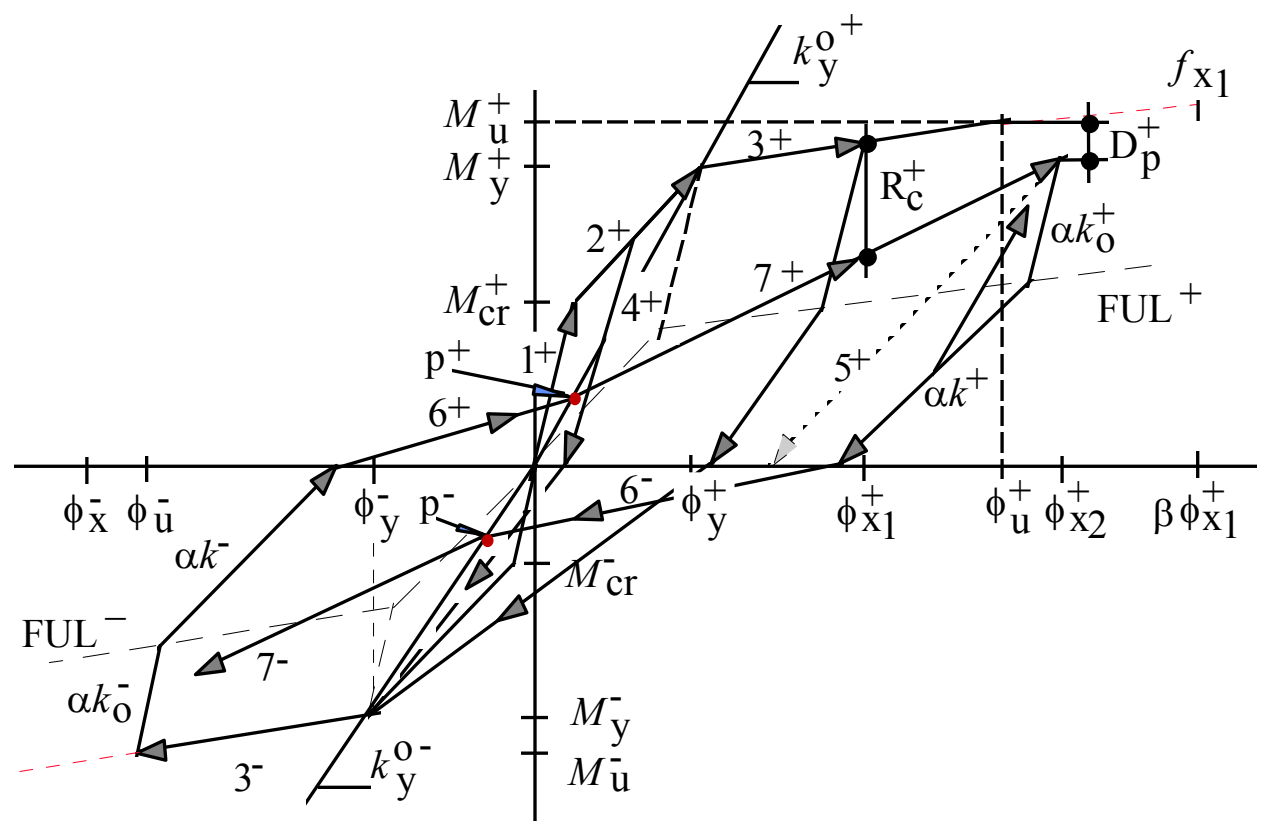

Figure 6. Cyclic law with non-linear unloading and $\left(\phi_{\mathrm{y}}-M_{\mathrm{y}}\right)$ as the first reversal focal point 


\section{NUMERICAL EXAMPLES}

The new proposed model has been validated on different structural members like beams, columns, subassemblies and frames. The members were subjected to monotonic, cyclic and dynamic loading. In order to compare the response given by the original and the new model, three relevant cyclic cases are shown in this paper.

As a first example, we consider a column subjected to quasi-static cyclic loading and to dynamic excitation. The responses of the original (Old 1D) model and the modified (New 1D) model are compared. As a second example a beam-column subassembly subjected to cyclic loading is considered. The numerical response of the original uniaxial model (Old 1D) and the new proposed model (New 1D) are compared to experimental results. Finally a short column is subjected to a spatial cyclic loading. This third example shows the capabilities of the uniaxial model for spatial cases subjected to constant or negligible variation of the axial force. Nevertheless, the interaction of flexion in both directions is neglected. The comparison between experimental and numerical results confirms the validity of this procedure.

\section{Column subjected to cyclic and dynamic loading}

The first application concerns a short column subjected to cyclic loading. Geometric characteristics and test set-up are given in Gauvin et all (1978). Basic concrete parameters are : $f_{\mathrm{c}}{ }^{\prime}=42 \mathrm{Mpa}, \varepsilon_{\mathrm{c}}{ }^{\prime}=0.0018$, and $E_{c}=33000 \mathrm{Mpa}$. For steel, the parameters are $: f_{y}=445 \mathrm{Mpa}, f_{u}$ $=540 \mathrm{Mpa}$, with ultimate strain $\varepsilon_{\mathrm{u}}=9 \%$.

The column is subjected to a series of cycles with increasing amplitudes. Figure 7.a shows the response at $\pm 20 \mathrm{~mm}$. The non-linear unloading leads to a greater residual strain in both directions. In consequence, the gain for these strains and for the dissipated energy is close to $43 \%$ and $53 \%$ respectively. It can be seen that the maximum strength is not affected. Hence, for a precise description of the cyclic behaviour of reinforced concrete members which exhibit current dissipation process, the introduction of non-linear unloading can be essential.

The same structure is subjected to several earthquakes of increasing amplitude lasting about $3.5 \mathrm{~s}$. In this work, the response at $1.9 \mathrm{~m} / \mathrm{s}^{2}$ is presented in Figure 7.b. The scatter for maximal amplitudes are $3.8 \%$ and $1.8 \%$ for the Old and New model accordingly. It can be noted that the principal difference is obtained when the seismic excitation disappears (after $3.5 \mathrm{~s}$ ). The unloading stiffness is slightly greater compared to the old model, resulting in a smaller hysteretic damping. 


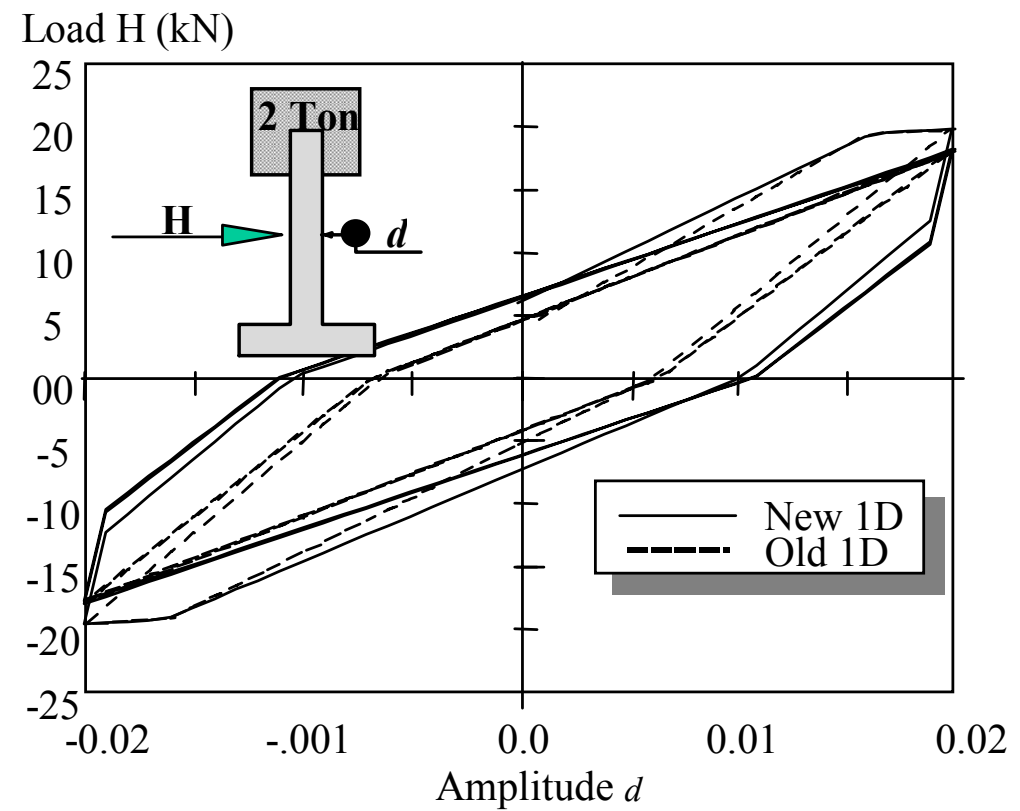

Figure 7a. Numerical comparison between the New and Old model
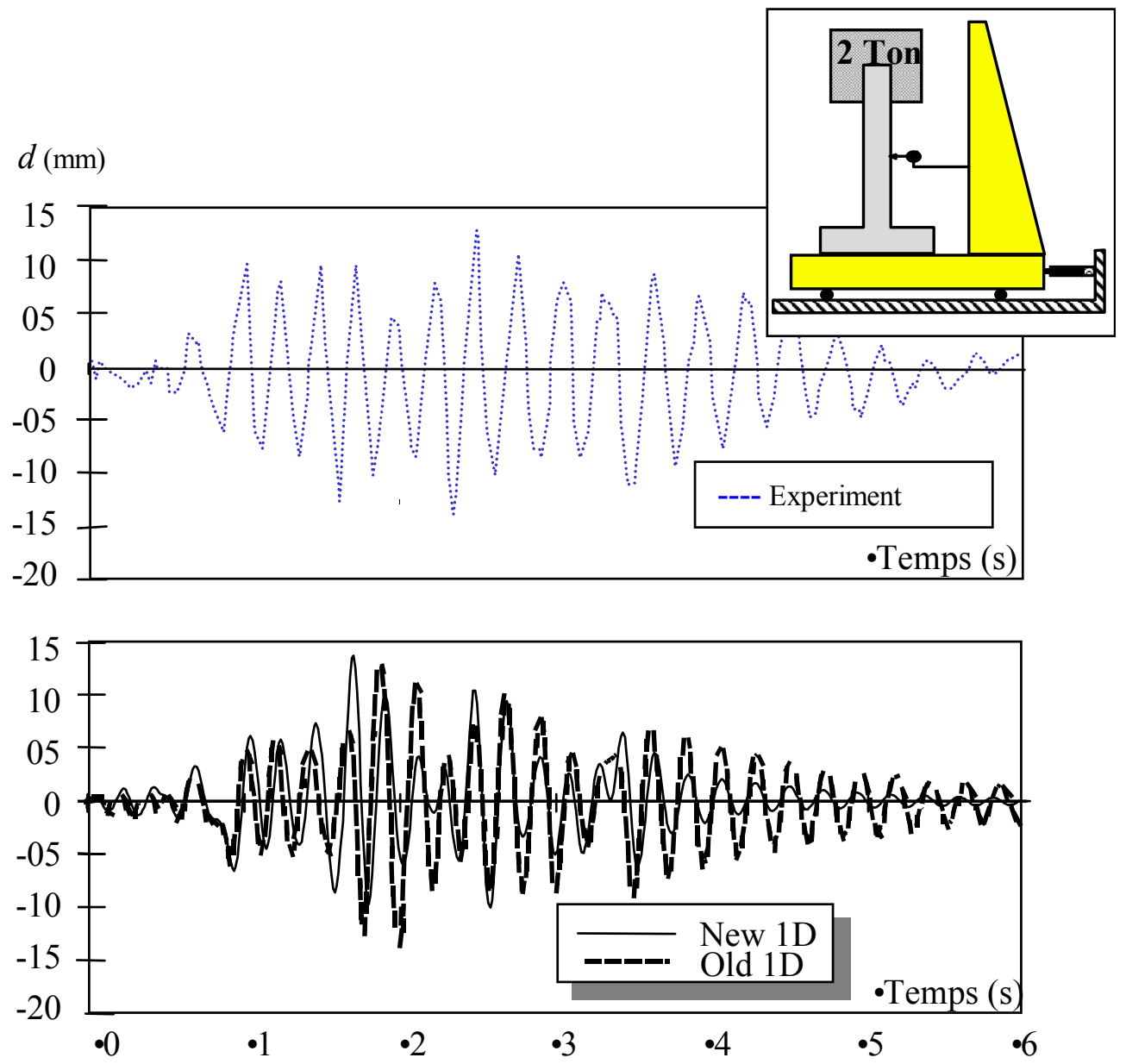

Figure $7 \mathrm{~b}$. Comparison of dynamic response 


\section{Beam-column subassembly}

The numerical investigation presented here concerns a beam-column subassembly subjected to reverse cyclic loading tested by Del Toro Rivera (1988). The specimen considered is an interior joint of a frame with $4 \mathrm{~m}$ bays and $2 \mathrm{~m}$ story heights. The geometric characteristics and the reinforced layout are described in Figure 8. Basic concrete parameters are: $E_{c}=37000 \mathrm{MPa}$, $f_{\mathrm{c}}^{\prime}=41 \mathrm{Mpa}, f_{\mathrm{t}}^{\prime}=4.1 \mathrm{Mpa}, v=0.2$ and steel parameters are $E_{s}=200000 \mathrm{MPa}$, yielding limit $f_{y:}$ : $490 \mathrm{MPa}(\phi 12), 440 \mathrm{MPa}(\phi 14), 550 \mathrm{MPa}(\phi 20)$. The boundary conditions are defined in such a way that the test can reproduce the response of a joint in a real building. First, a vertical prestressing load $(200 \mathrm{kN})$ is applied to the column and an initial flexural load is introduced by loading vertically $(22 \mathrm{kN})$ the beam ends noted as $\Delta$ in Figure 8 . These loads simulate the dead weight of the building and the service loads acting on the floor. Beam and column members have been divided in finite elements of uniform length $(0.5 \mathrm{~m})$.

The vertical displacements of the beam ends are prevented and an alternating horizontal displacement is imposed on the base of the column simulating the seismic action. The loading consists of a series of cycles of increasing amplitudes; a set of five cycles is carried out in order to check the stability of the structural properties under repeated loading. The first set of cycles has an amplitude of $\mathrm{d}=10 \mathrm{~mm}$ and represents a service load. The following cycles $(\mathrm{d}=13,26,39$ $\mathrm{mm})$ bring the structure into the post-elastic domain, and the last cycles $(\mathrm{d}=52,65 \mathrm{~mm})$ produce a softening behaviour of the structure.

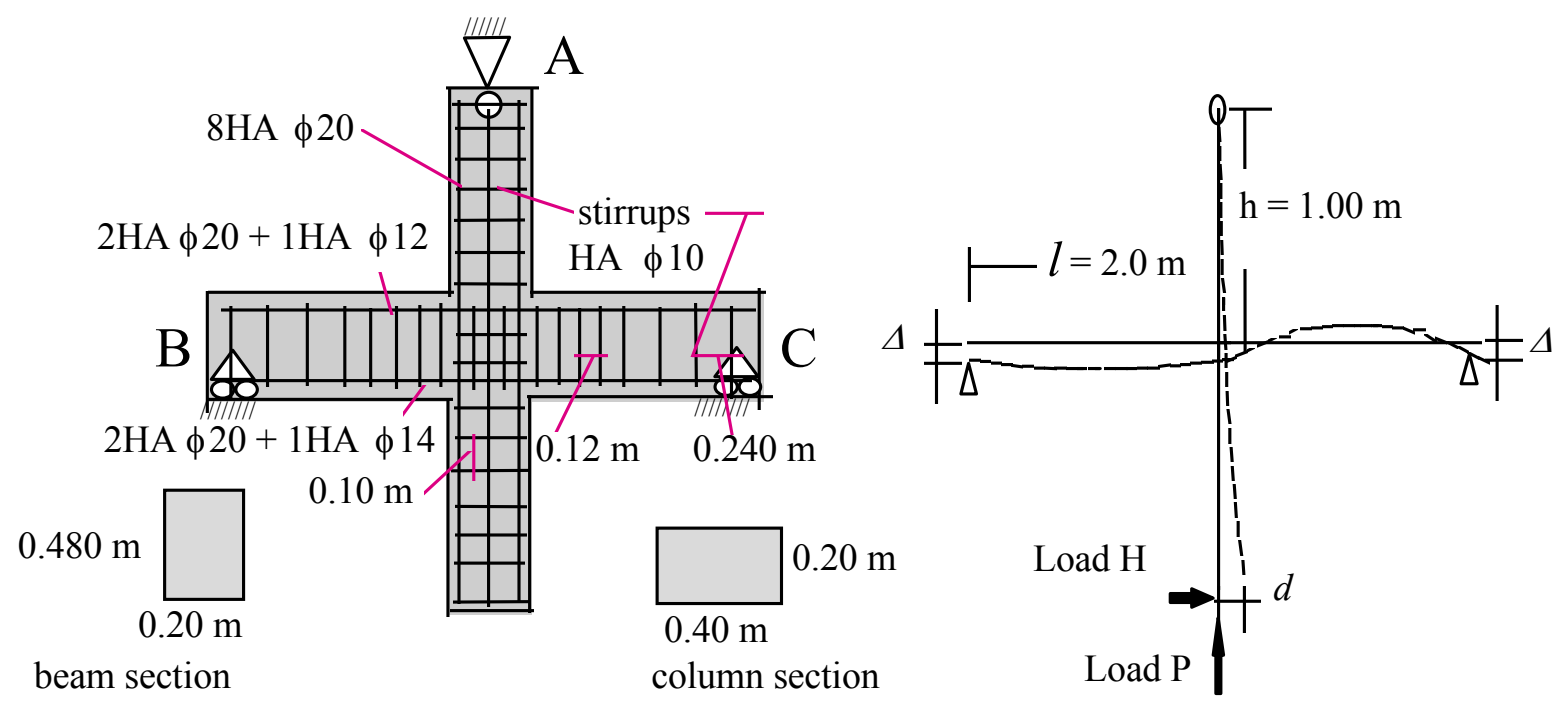

Figure 8. Geometric characteristics of the sub-assembly and loading conditions 


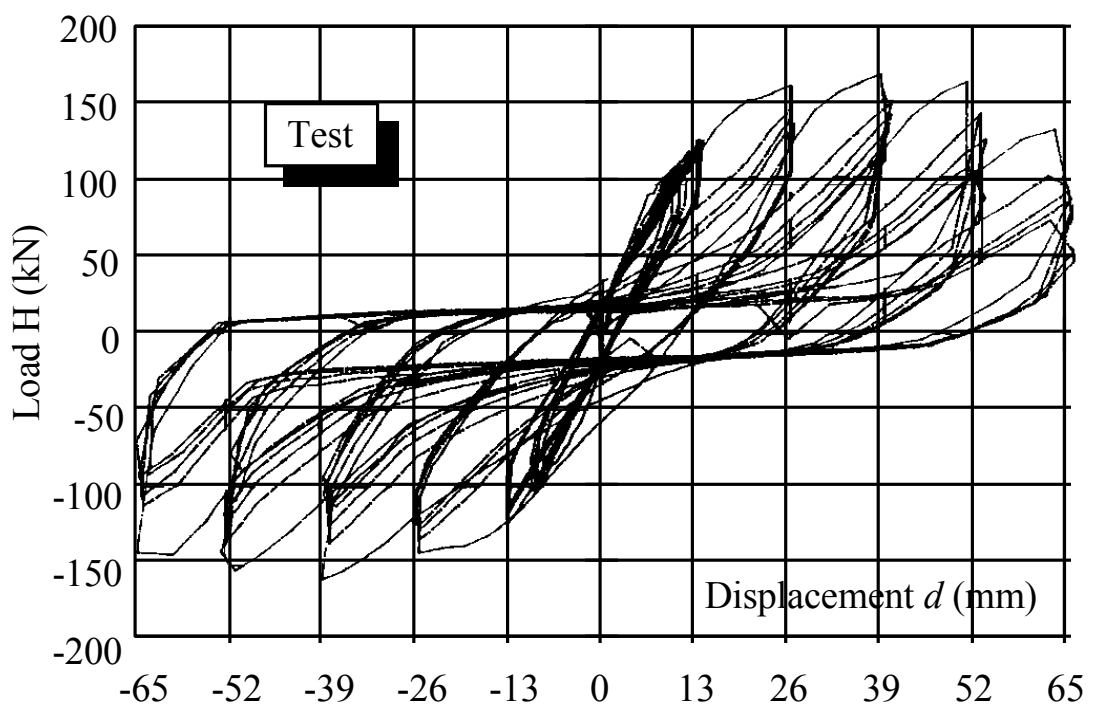

Figure. 9a. Complete experimental results

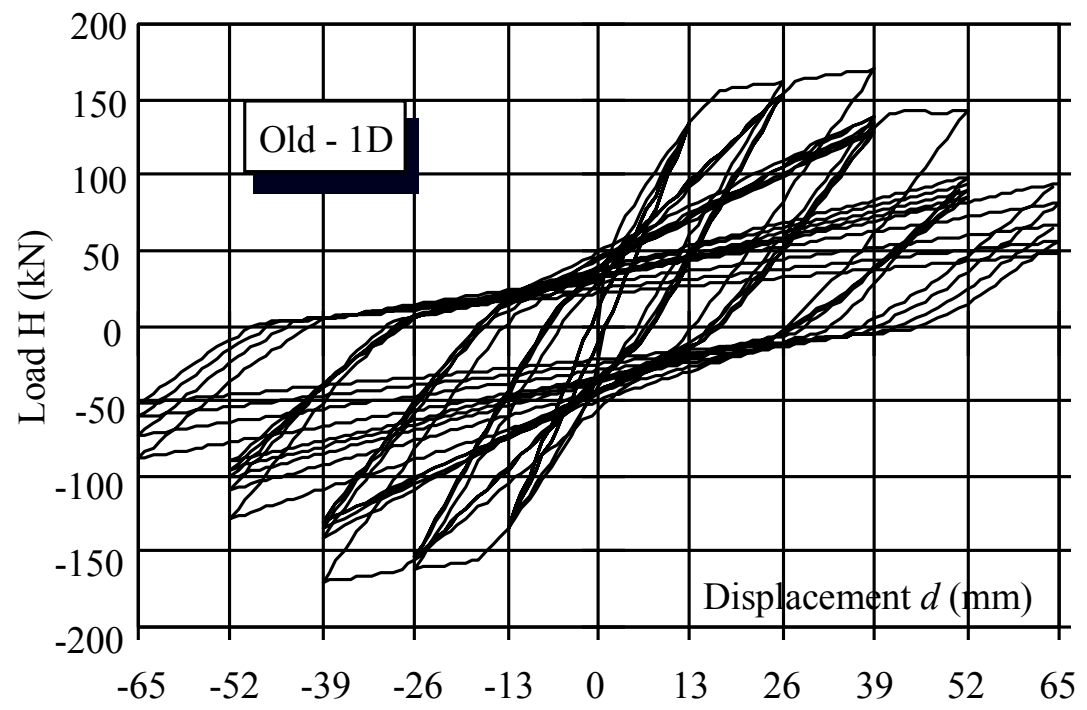

Figure 9b. Cyclic response given by the original model

The global response of the subassembly concerns the history of the horizontal displacement $d$ at the base of the column, versus the horizontal load $H$. The numerical predictions for a set of five cycles at $( \pm)$ different deformation levels are compared with the experimental results. Figure 9 shows good agreement in the evolution of the stiffness degradation and of the residual deformations. The maximum strength by cycle for the imposed displacement, agrees quite well with the experimental results. This can be done due to the same envelope curves in both models. However, the observed cyclic deterioration is more accentuated in the test than that observed in the models. Table 1 compares the experimental versus numerical values of these two models. It 
Table 1. Experimental / numerical comparison for \pm 0.026 to \pm 0.065 m amplitudes

\begin{tabular}{|c|c|c|c|c|c|c|c|c|c|c|c|c|}
\hline & \multicolumn{4}{|c|}{ Experiment } & \multicolumn{4}{|c|}{ Old 1D } & \multicolumn{4}{|c|}{ New 1D } \\
\hline $\begin{array}{l}\text { Amplitude } \\
\text { (mm) }\end{array}$ & 26 & 39 & 52 & 65 & 26 & 39 & 52 & 65 & 26 & 39 & 52 & 65 \\
\hline $\begin{array}{l}\mathrm{H}_{\max }(+) \\
(\mathrm{kN})\end{array}$ & 160 & 170 & 162 & 145 & 160 & 170 & 145 & 95 & 159 & 170 & 160 & 99 \\
\hline $\begin{array}{l}\mathrm{H}_{\max }(-) \\
(\mathrm{kN})\end{array}$ & 145 & 160 & 155 & 162 & 162 & 170 & 125 & 90 & 160 & 162 & 160 & 100 \\
\hline $\begin{array}{l}\text { Residual } \\
\text { strain }(+) \\
\text { mm }\end{array}$ & 10 & 25 & 38 & 52 & 8 & 17 & 30 & 43 & 15 & 22 & 35 & 51 \\
\hline $\begin{array}{l}\text { Residual } \\
\text { strain (-) } \\
\text { mm }\end{array}$ & 9 & 24 & 35 & 54 & 8 & 16 & 29 & 48 & 13 & 23 & 40 & 51 \\
\hline
\end{tabular}

can be noted that the maximum strength is quite similar in both cases. The difference between all these values is less than $10 \%$. In contrast, for the last cycle, where the capacity of the structure is severely reduced, the maximum difference becomes $31 \%$ and $60 \%$ for the new and old model accordingly. For the cycles of maximum amplitude, it can be observed that the greatest difference for residual strains are $14 \%$ for the new model and $37 \%$ for the old model. It is important to note that in the last cycles of the new model, the reduced strength is close to the cracking load, in consequence, the bilinear unloading branch disappears. The assumption of the first unloading limit (Figure 4) is responsible of this effect. Furthermore, the bilinear unloading branch produces a greater residual strain as was schematized in Figure 6. The new model allows a better description of the residual strains and of the energy dissipation (Figure 9c). In all the studied cases, the gain in the dissipated energy is close to $50 \%$ compared to the old model.

\section{RC column subjected to a spatial cyclic loading}

A reinforced concrete column element with $1.49 \mathrm{~m}$ length, tested by Bousias (1992), intend to simulate part of a column between the foundation and the point of inflection. The square section and layout is shown in Figure 10. The axial force and biaxial horizontal displacements imposed on the free top of the structure during the loading history are shown in the same figure. The displacement path is what is usually called a "shrinking path", since after an important displacement imposed to the structure, there is a progressive movement in both directions into the initial zero displacement position. The loading follows a four squares displacement path centered at the origin of half-side lengths equal to $0.10,0.08,0.06$, and $0.04 \mathrm{~m}$ in each direction. 


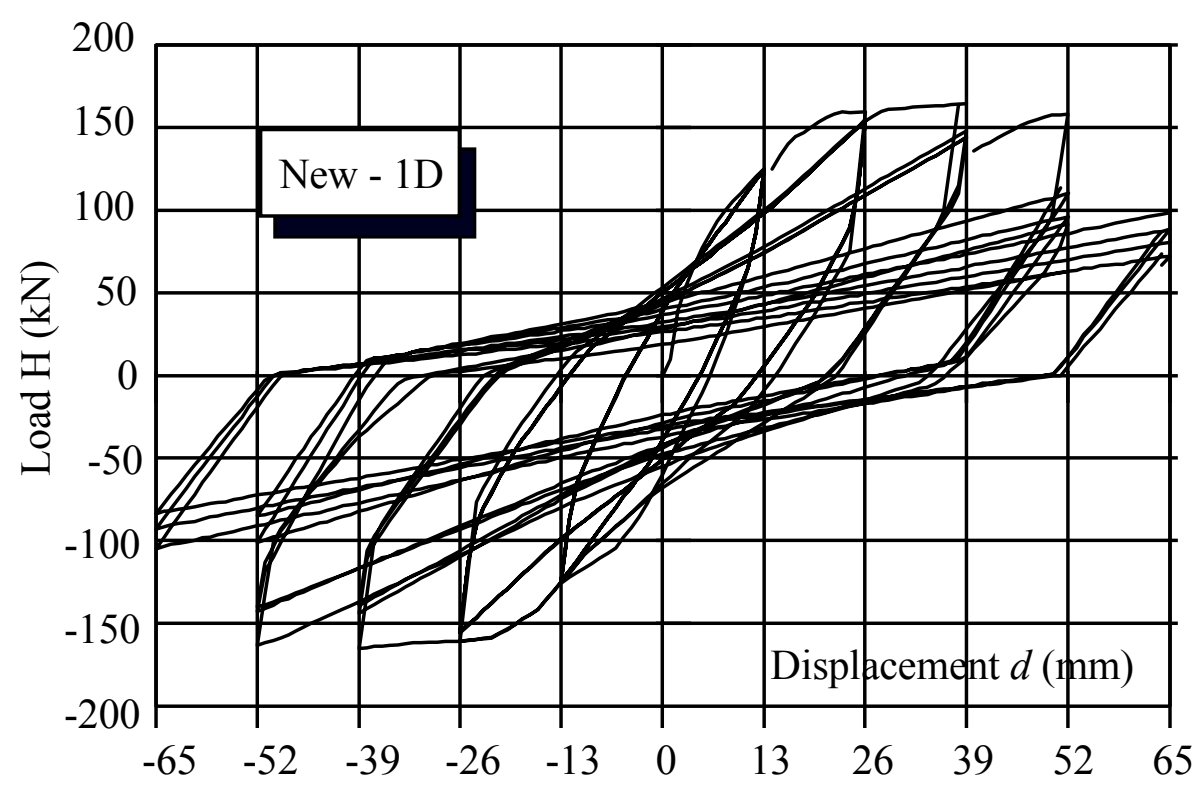

Figure 9c. Cyclic response given by the new 1D model

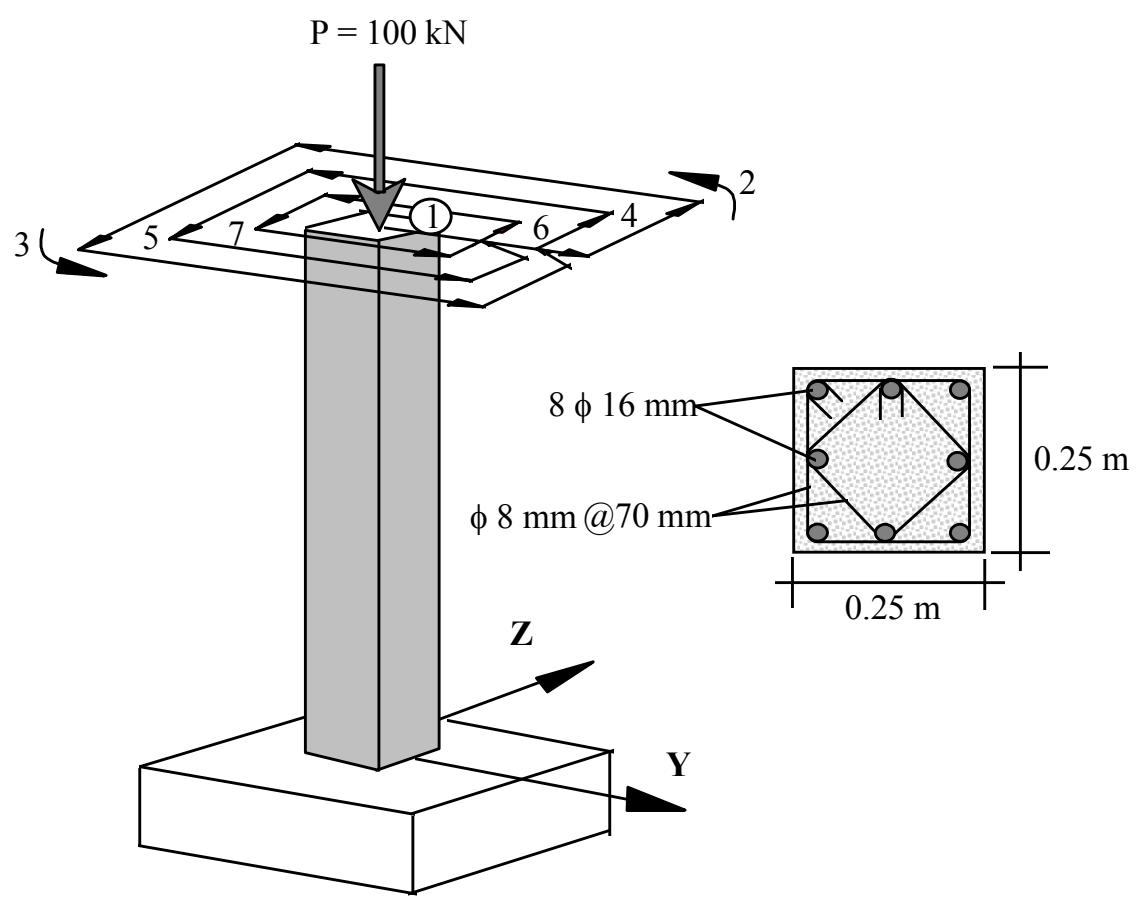

Figure 10. RC column subjected to spatial cyclic loading 
The adopted material characteristics are the mean values found from the laboratory tests made on concrete and steel specimens (Guedes et al., 1992). For unconfined concrete a compression strength of $30 \mathrm{Mpa}$ and the corresponding strain $0.2 \%$ were considered. For the concrete core a confinement factor of 1.343 was found during the envelope moment-curvature curve definition versus 1.33 adopted by Guedes et al. (1992) This factor is determinant during the evaluation of the maximum strength of the section (Miramontes et al., 1996). Consequently, the proximity between these values guarantees a reliable definition of the characteristic curve. For the steel the adopted characteristics were : yield stress 440.0 Mpa, Young's modulus 203.0 Gpa, hardening and ultimate strain of $0.8 \%$ and $13.0 \%$, respectively, with an ultimate stress of $760 \mathrm{Mpa}$.

The structure was divided in six elements instead of seven elements reported by Guedes et al. (1992). Minimum size element in the global model is limited to mid-height section, consequently the first two elements at bottom were taken as one. Increasing lengths from the base to the free top are: $0.15,0.15,0.20,0.25,0.35,0.39 \mathrm{~m}$.

As was noted by Guedes et al. (1992), "After the first square path, almost all the concrete is destroyed and the response curve is mainly due to the steel". That means that steel law is dominant in observed results. In global models, member behaviour is modeled by an homogeneous RC section, therefore, stiffness degradation and strength deterioration are quite different from a cyclic steel law, which can be explicitly described by a multilayered approach.

In the proposed global model, the histeretic law takes implicitly the steel behaviour, therefore, the shape of loops concerns a reinforced cross section and not the cyclic loop of the steel alone. Consequently, in this example case, stiffness degradation and dissipated energy cannot be expected to be close to experimental values. However, good agreement is found for maximum value forces by cycle in both models. In fact, only one peak strength gives a scatter of $-9.4 \mathrm{kN}$, while other dispersions remain under this value (Figures 11-12). That means that the strength reduction takes into account the degradation process of the composed material.

In the original model, the residual strains differ generally in $40 \%$ in both directions of loading. For loads near to failure, a strong unloading degradation has been imposed to the model. Furthermore, subsequent unloading is governed at least by the same damage index. As a result, the same difference in residual strains is found through all cyclic loading (Figures 11-12). In the new model, the increase of dissipated energy produces more realistic values. The shape of the hysteretic curves are close to the observed results and residual strains at unloading are closer to experimental values. 


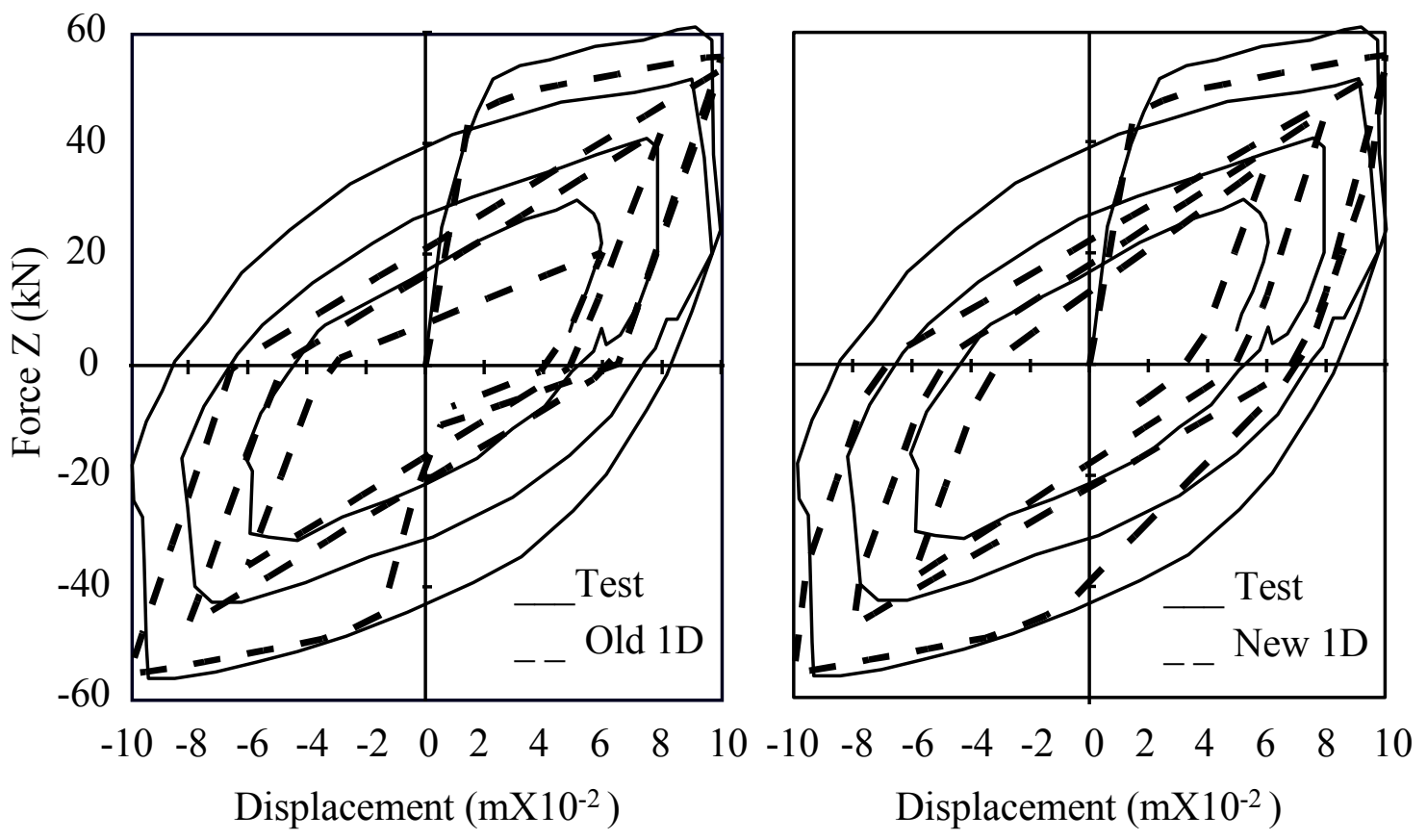

Figure 11. Experimental versus numerical cyclic response in $\mathrm{Z}$ direction
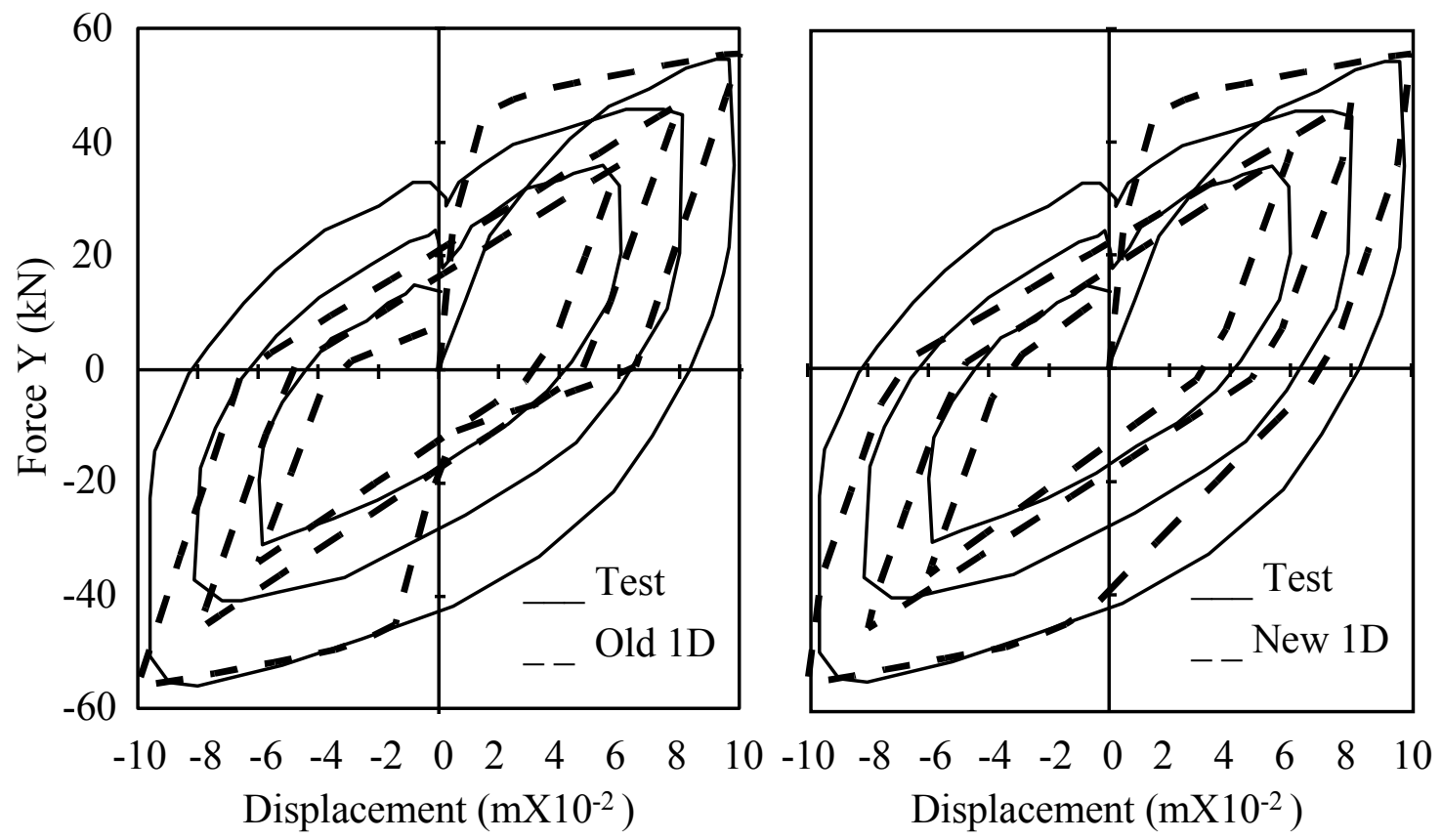

Figure 12. Experimental versus numerical cyclic response in $\mathrm{Y}$ direction 
Table 2 shows the experiment/numerical results for all maximum forces corresponding to the imposed displacements. It can be noted that the greatest scatter for strength values is observed in the $\mathrm{Z}$ direction. The difference represents $7 \%$ in this direction versus $2 \%$ for the $\mathrm{Y}$ direction. This difference shows the effect of the interaction between $\mathrm{M}_{\mathrm{y}}-\mathrm{M}_{\mathrm{z}}-\mathrm{N}$ which is not taken into account by the uncoupled uniaxial model. The residual strains per cycle are presented in Table 3 . Concerning these residual strains, the prediction of the cyclic response observed in the new model is better. Moreover, the energy dissipation is closer to experimental results. It can be noted that the cracking point should not be used as the first focal point after the first unloading as in Figure 1. This assumption produces the pinched shape of the first cycle in the old model. In order to improve the prediction of the new model, it is preferable to define the yielding point as the first focal point even for loading below the yielding of steel (Figure 6).

Table 2. Maximun strength values

\begin{tabular}{|c|c|c|c|c|c|c|c|}
\hline \multicolumn{4}{|c|}{$\mathrm{Z}$ direction } & \multicolumn{4}{|c|}{ Y direction } \\
\hline Cycle & Experiment & Old 1D & New 1D & Cycle & Experiment & Old 1D & New 1D \\
\hline & $\mathrm{kN}$ & $\mathrm{kN}$ & $\mathrm{kN}$ & & $\mathrm{kN}$ & $\mathrm{kN}$ & $\mathrm{kN}$ \\
\hline $1^{+}$ & 59.00 & 55.61 & 55.64 & $1^{+}$ & 55.00 & 55.61 & 55.64 \\
\hline $2^{+}$ & 53.00 & 53.25 & 53.51 & $2^{+}$ & 45.00 & 46.81 & 47.86 \\
\hline $3^{+}$ & 41.00 & 42.57 & 45.63 & $3^{+}$ & 35.00 & 36.06 & 37.98 \\
\hline $1^{-}$ & 58.00 & 55.61 & 55.68 & $1^{-}$ & 57.00 & 55.61 & 55.65 \\
\hline $2^{-}$ & 45.00 & 46.80 & 46.64 & $2^{-}$ & 43.00 & 45.80 & 46.97 \\
\hline $3^{-}$ & 30.00 & 36.15 & 33.72 & $3^{-}$ & 30.00 & 33.94 & 33.71 \\
\hline
\end{tabular}

Table 3. Residual displacements values

\begin{tabular}{|c|c|c|c|c|c|c|c|}
\hline \multicolumn{4}{|c|}{$\mathrm{Z}$ direction } & \multicolumn{4}{|c|}{ Y direction } \\
\hline Cycle & Experiment & Old 1D & New 1D & Cycle & Experiment & Old 1D & New 1D \\
\hline & $\mathrm{m}$ & $\mathrm{m}$ & $\mathrm{m}$ & & $\mathrm{m}$ & $\mathrm{m}$ & $\mathrm{m}$ \\
\hline $1^{+}$ & 0.080 & 0.065 & 0.067 & $1^{+}$ & 0.082 & 0.068 & 0.072 \\
\hline $2^{+}$ & 0.070 & 0.063 & 0.066 & $2^{+}$ & 0.065 & 0.047 & 0.067 \\
\hline $3^{+}$ & 0.050 & 0.047 & 0.049 & $3^{+}$ & 0.043 & 0.030 & 0.034 \\
\hline $1^{-}$ & 0.081 & 0.067 & 0.072 & $1^{-}$ & 0.080 & 0.068 & 0.072 \\
\hline $2^{-}$ & 0.065 & 0.050 & 0.055 & $2^{-}$ & 0.063 & 0.050 & 0.068 \\
\hline $3^{-}$ & 0.043 & 0.030 & 0.033 & $3^{-}$ & 0.042 & 0.030 & 0.034 \\
\hline
\end{tabular}




\section{CONCLUSION}

An adequate description of the cyclic behaviour of $\mathrm{RC}$ structures depends strongly on a fine estimation of the energy dissipation. In this paper, the Lagrange multipliers applied to a nonlinear dynamic analysis based on the averaged Newmark method was presented. The material non-linearities are described by a moment-curvature relationship. The non-linear analysis of whole structures subjected to dynamic loads represents a high constraint due to the volume of non-linear calculations needed to integrate the equilibrium equations for each time step, and consequently, a precise choice between different scale description arises. In a global approach $(N, \varepsilon ; V, \gamma ; M, \phi$ relationships), the integration of stress at cross section level is eliminated and the number of points defining the behavioural law is reduced. The loss of local information, the constant value of the axial force, and the uncoupled assumption of forces represent the principal drawback of uniaxial models. Nevertheless, global approaches have a wide margin of applicability for structures composed by beams and columns.

The proposed cyclic model benefits the validated features of a previous uniaxial model. This model accounts for cracking of concrete, yielding of steel and crushing of concrete at maximum strength. The model considers the strength reduction and stiffness degradation due to cyclic loading, the pinching of loops due to shear stress and bond strength deterioration, and the effect of a constant axial load. Another feature of the model is given by a cyclic parameter which allows the description of a continuous degradation process. In addition, the implementation of non-linear unloading allows a more realistic numerical evaluation of residual strains and energy dissipation. The first example represents a theoretical comparison between the Old and the New model. The second example corresponds to a full cyclic test. All the different stages of the cyclic behaviour can be observed : pre-yielding, post-yielding and softening. The new model allows a better evaluation of residual strains due to non-linear unloading, while the increase of energy dissipation represents a good agreement with experimental results. The experimental vs. numerical comparison of the third example shows the importance of the correct description during unloading process. The great difference in the dissipated energy described by the original and the new 1D model enhance the importance of the non-linear unloading modelling.

\section{ACKNOWLEDGMENT}

The new model has been implemented and validated by internet from the Universidad Autónoma de Zacatecas at México to the Institut National des Sciences Appliquées de Lyon at France. All the facilities, encouragements and help are greatly acknowledged. It is also acknowledged the ECOS-NORD and ANUIES support to the project M99-U01. 


\section{REFERENCES}

Bozinovski, Z. (1995). 'Experimental investigations of large panel reinforced concrete systems as a basis for aseismic design of stable and economic structures', Proceedings of the fith SECED Conference. European seismic design practice. Research and application. A.S. Elnashai (ed). Chester. UK., p 263-270

Bousias, S. (1992). 'Load path effects in reinforced concrete column - biaxial bending with axial force', Technical note No. I.92.63, Commission of the European Communities, Joint Research Centre, Ispra Site, Italy.

CEA, Commissariat à l'Énergie Atomique, (1990). Castem2000, Guide d'Utilisation, Saclay, France.

Cheok, G., Stone, W. and Kunnath, S.K. (1998). 'Seismic Response of Precast Concrete Frames with Hybrid Connections'. ACI Structural Journal. Vol. 95, No.5

Chronopoulos, M. P. \& Vintzileou, E. (1995). 'Confinement of RC columns', Proceedings of the fith SECED Conference. European seismic design practice. Research and application. A.S. Elnashai (ed). Chester. UK. p 341-348

Del Toro Rivera, R. (1988). 'Comportement des noeuds d'ossature en béton armé sous sollicitations alternées', Thèse de Doctorat. Ecole Nationale des Ponts et Chaussées, Paris, France, 150 p.

Gauvin, J., Jeandidier, C., Gauvert, J.C., Queval, J.C. and Vaghi, H., (1978), 'Seismic tests of RC columns', Saclay, France, CEA, 136 p'., Technical Report C.E.A.-D.M.T/78/177

Guedes, J., Pegon, P. \& Pinto, A. V. (1992). 'A fibre/Timoshenko beam element in castem 2000', Rapport No 5090-92-11 TS ISP F. Applied Mechanics Unit, Institute for Safety Technology, Joint Research Centre, Commission of the European Communities, I-21020 Ispra (VA) Italy.

Koh, C. G. Ang, K. K. and Zhang L. (1997). 'Effects of repeated loading on creep deflection of reinforced concrete beams', Engrg Struct, Vol. 19, No 1, p. 2-18

Kunnath, S.K., Mander, J.B. and Lee, F. (1997) Parameter Identification for Degrading and Pinched Hysteretic Structural Concrete Systems. Engineering Structures, Vol. 19, No 3, pp.224-232.

Miramontes, D., Merabet, O. \& Reynouard, J.M. (1996). 'Hysteretic global model for the seismic analysis of RC frames', Earthquake Engineering and Structural Dynamics, Vol. 25, p. 671-688

Miramontes, D. (1996). 'Modèle global de poutre pour l'analyse sismique des portiques en béton armé : Approche phénoménologique et approche en plasticité', Thèse de Doctorat, INSA-Lyon, France, $261 \mathrm{p}$.

Miramontes, D., Merabet, O. \& Reynouard, J.M. (1996). 'Kinematic single surface global model for the seismic analysis of reinforced concrete frames'. 14th Conference on Structural mechanics in 
reactor technology, Espace Tête d'Or, Lyon, France. 1997, p 291-298

Mork, K.J., (1994). 'Response analysis of reinforced concrete structures under seismic excitation', Earthquake engineering and structural dynamics, Vol. 23, p. 33-48

Park, R., Kent, D. Ch. \& Sampson, R. A. (1972). 'Reinforced Concrete Members with Cyclic Loading'. Journal of Structural Division. Proceedings of the American Society of Civil Engineers, , Vol. 98, ST7, p. 1341-1359

Park, R., Priestley, M. J. N. \& Gill W. D. (1982). 'Ductility of square-confined concrete columns', Journal of the Struct. Division, Proc. of the American Society of Civil Engineers, ASCE. Vol. 108, No. ST4, p. 929-950

Roufaiel, M. S. L. and Meyer, C., (1987). 'Analytical modelling of hysteretic behaviour of R/C frames', Journal of Struct. Engrg, ASCE. Vol. 113, p. 429-444

Sinha, B.P., Grestle, K.H. \& Tulin, L.G. (1964). 'Stress-Strain Relationships for concrete under cyclic loading'. Journal ACI, Vol. 61. No. 2. p. 195-211

Spacone, E., Filippou, F.C. and Taucer, F.F. (1996). "Fibre Beam-Column Model for Non-linear Analysis of R/C Frames : Part I. Formulation." Earthquake Engineering and Structural Dynamics, Vol. 25, 711-725.

Spacone, E., Filipou, F.C and Taucer, F.F. (1996). "Fibre beam-Column Model for Non-linear Analysis of R/C Frames : Part II Applications." Earthquake Engineering and Structural Dynamics, Vol. 25, 727-742.

Takeda, T., Sozen, M.A., Nielsen, N.N., (1970). 'Reinforced concrete response to simulated earthquakes', ASCE Journal of Structural Div, Vol. 96, ST12, p. 2557-2573

Taucer, F.; Spacone, E.; Filippou, F. C. , (1991). 'A fiber beam-column element for seismic response analysis of reinforced concrete structures', CB/EERC-91/17, Berkeley: Earthquake Engineering Research Center, University of California, Dec. 1991, 142 pages

Wolf, J. P. and Song, C. (1996). Finite-Element Modelling of Unbonded Media, John Wiley and Sons, 331 p. UK 